Revista de Derecho Público: Teoría y Método Marcial Pons Ediciones Jurídicas y Sociales Vol. 4 | 2021 pp. 125-152 Madrid, 2021

DOI:10.37417/RPD/vol_4_2021_642

(C) Cristian Ismael Montero Cartes

Recibido: 08/07/2021 | Aceptado: 14/10/2021

Editado bajo licencia Creative Commons Attribution 4.0 International License.

\title{
REFLEXIONES EN TORNO A LA CONSTRUCCIÓN DE LA NOCIÓN DE SANCIÓN JURÍDICA: EL INDISPENSABLE RECURSO A LA TEORÍA GENERAL A OBJETO DE DISTINGUIR LA SANCIÓN ADMINISTRATIVA DE LA PENA JUDICIAL
}

\author{
REFLECTIONS AROUND THE CONSTRUCTION OF THE NOTION \\ OF LEGAL SANCTION: THE ESSENTIAL RESOURCE \\ TO THE GENERAL THEORY IN ORDER TO DISTINGUISH THE \\ ADMINISTRATIVE SANCTION FROM THE JUDICIAL PENALTY
}

Cristian Ismael Montero Cartes*

RESUMEN: Tras constatar que el entendimiento tradicional de las sanciones jurídicas se ha articulado a partir de, y en función a, la teoría del Derecho penal (cuestión que, al mismo tiempo, condiciona la configuración de otros tipos de sanciones como las administrativas y explica, siquiera en parte, la asunción de un supuesto ius puniendi único del Estado), el autor plantea que un análisis correcto y fructífero del concepto de sanción administrativa exige insertarla en el contexto más amplio de las sanciones jurídicas, en tanto se trata de una especie de esta — como, asimismo, la pena judicial— y, por tanto, su construcción teórico-dogmática debe realizarse, previamente, a partir de la teoría general del Derecho.

PALABRAS CLAVE: sanción jurídica; teoría del derecho; Derecho administrativo sancionador; Derecho penal; ius puniendi.

* Investigador independiente. Abogado. Licenciado en Ciencias Jurídicas y Sociales por la Universidad de Concepción, Chile; Magíster en Derecho Público por la Pontificia Universidad Católica de Valparaíso, Chile, y Máster Universitario en Derecho Público, Universidad Carlos III de Madrid, España.crmontero@udec.cl

En el texto se emplean las siguientes abreviaturas: STC; Sentencia del Tribunal Constitucional Chileno, CP; Constitución Política Chilena y STJUE; Sentencia del Tribunal de Justicia de la Unión Europea. 
ABSTRACT: After verifying that the traditional understanding of legal sanctions has been articulated from, and based on, the theory of criminal law (a question that, at the same time, conditions the configuration of other types of sanctions such as administrative ones and explains, even in part, the assumption of a unique ius puniendi of the State), the author argues that a correct and fruitful analysis of the concept of administrative sanction requires inserting it into the broader context of legal sanctions, insofar as it is a kind of this -as, likewise, the judicial penalty-and, therefore, its theoretical-dogmatic construction must be carried out, previously, from the general theory of law.

KEYWORDS: legal sanction; theory of law; administrative sanctioning law; criminal law; ius puniendi.

SUMARIO: 1. EL DERECHO Y LAS SANCIONES JURÍDICAS COMO TÉCNICAS DE CONTROL SOCIAL.-2. LAS SANCIONES JURÍDICAS COMO RAZONES PARA LA ACCIÓN E INSTRUMENTO QUE PERSIGUE LA EFICACIA EN EL CUMPLIMIENTO DE LAS REGLAS JURÍDICAS.-3. LA FORMA TRADICIONAL DE ARTÍCULACIÓN DEL CONCEPTO DE SANCIÓN JURÍDICA; 3.1. El corolario de esta forma de construcción: la asunción de un ius puniendi (derecho a castigar) único del Estado; 3.2. Progresiva "penalización del Derecho administrativo» y de «administrativización del Derecho penal».—4. LA EMERGENCIA DE LA OBJECIÓN DEL IUS PUNIENDI ÚNICO Y LA ARTICULACIÓN DE LAS SANCIONES JURÍDICAS DESDE LA TEORÍA GENERAL.-5. LA IMPORTANCIA DE LA DEBIDA ARTÍCULACION DE LAS SANCIONES ADMINISTRATIVAS: SU CARÁCTER DE INSTRUMENTO QUE PERSIGUE LA CONSECUCIÓN DE POLÍTICAS Y PROGRAMAS NORMATIVOS.-6. BIBLIOGRAFÍA.

\section{EL DERECHO Y LAS SANCIONES JURÍDICAS COMO TÉCNICAS DE CONTROL SOCIAL}

Todo orden social supone cierta uniformidad de conductas que en «alguna medida hace previsibles, esto es, típicas, las reacciones de los individuos ante situaciones igualmente típicas» ${ }^{1}$. En efecto, la vida en sociedad requiere de un sistema de reglas o directrices que, operando como orientación y guía, permitan fijar las condiciones -siquiera mínimas- para la interacción entre los miembros de la colectividad, señaladamente, con miras a garantizar el libre desarrollo de la personalidad y la conservación y funcionamiento social ${ }^{2}$.

En ese contexto, las reglas dadas por la sociedad operan, tal como ha apuntado Radcliffe-Brown, como motivos para que los individuos regulen su conducta; y cumplen su cometido, vale decir, son efectivas por dos razones, primero, por el deseo de que sus acciones reciban aprobación de la sociedad (evitando, así, la imposición de sanciones o, en su caso, para obtener alguna recompensa) y, segundo, pues las personas aprenden «a reaccionar hacia modos particulares de conducta con juicios

${ }_{1}$ Guiseppe LUMIA, Principios de Teoría e ideología del Derecho (traducción por Alfonso RUIZ MIGUEL), Editorial Debate, Madrid, 1978, p. 12.

2 Vid., Antonio FERNÁNDEZ-GALIANO y Benito DE CASTRO CID, Lecciones de Teoría del Derecho y Derecho Natural, reim. revisada, Editorial Universitas, Madrid, 1994, pp. 74-76. 
de aprobación o desaprobación del mismo modo que sus compañeros, y mide, por tanto, su propia conducta, tanto la pasada como la futura, de acuerdo con normas que se ajustan más o menos estrechamente a las que prevalecen en la comunidad a la que pertenece» ${ }^{3}$.

Pues bien, la constatación de la imposibilidad de pretender que baste con la mera adhesión voluntaria (interiorización) de todas y cada una de las reglas para que ellas sean obedecidas es lo que ha llevado a la construcción de mecanismos y técnicas que persiguen prevenir o impedir comportamientos que no se ajusten a aquellas (calificadas como conductas desviadas) ${ }^{4}$, cuyo nombre genérico es el de control social ${ }^{5}$.

$\mathrm{Al}$ respecto, cabe recordar que desde hace varios siglos ha sido una opinión más o menos asentada en la tradición jurídica que la coerción o coacción constituye una nota diferenciadora del Derecho 6 : en efecto, se ha puesto de relieve que destacados filósofos, entre los que se incluyen a Spinoza, Kant y otros, concebían al Derecho como una forma de control social, como la «ordenación del comportamiento humano a través de la coerción» ${ }^{7}$.

En virtud de dicho control se pretende asegurar que las personas ahormarán su comportamiento a ciertas reglas ( "normas de conducta» ${ }^{8}$ ) en sus relaciones sociales (fijando, así, límites a la libertad de acción), de suerte que, frente al incumplimiento o infracción de las expectativas de la conducta esperada, la comunidad organizada se encontrará facultada para ejercer específicos mecanismos de reacción ${ }^{9}$. El control social aparece, pues, como un «conjunto de instrumentos y técnicas dirigidos a presio-

3 Para este autor las sanciones son de tal relevancia que la conciencia del individuo, en un sentido amplio, es «el reflejo en el individuo de las sanciones de la comunidad.» Alfred R. RADCLIFFEBROWN, Estructura y función en la sociedad primitiva (traducción por Ángela PÉREZ), Planeta-De Agostini, Barcelona, 1986, pp. 233-234.

4 Vid., FERNÁNDEZ-GALIANO y DE CASTRO CID, 1994: 77.

5 Vid., Darío MELOSSI, El Estado del control social. Un estudio sociológico de los conceptos de estado y control social en la conformación de la democracia (traducción por Martín MUR UBASART), Siglo Veintiuno editores, México D.F., 1992, pp. 160 y ss., y, en el ámbito del Derecho, Ramón SORIANO, Sociología del Derecho, Ariel, Barcelona, 1997, pp. 318 y 338.

6 Vid., en tal sentido, Charles A. MORAND, «La sanction», en Travaux CETEL, núm. 36, 1990, p. 3. (Accesible en https://archive-ouverte.unige.ch/unige:4959), y Neil MAcCORMICK, Derecho legal y Socialdemocracia. Ensayos sobre filosofía jurídica y politica (traducción por María Lola GONZÁLEZ SOLAR), Tecnos, Madrid, 1990, p. 188.

7 «Spinoza's theory of the nature of law is a clear anticipation of an idea which han been an influential one from Kant to the present day. It is the theory which conceives of law as a form of social control, as the device which has as its aim the ordering of human behavior through coerción.» Huntington CAIRNS, Legal Philosophy from Plato to Hegel, Johns Hopkins University Press, Baltimore, 1949 , p. 277.

8 FERNÁNDEZ-GALIANO y DE CASTRO CID, 1994: 79. Como bien agregan los autores, en las sociedades actuales resulta cada vez más complejo fijar pautas comunes o reglas de conducta para todos los miembros de la colectividad por razón de la creciente diversidad y pluralidad de valores e intereses, lo que dificulta el ejercicio de la función de control social (pp. 79-80).

9 Cfr. Francisco MUÑOZ CONDE, Derecho Penal y Control Social, Fundación Universitaria de Jerez, Madrid, 1985, p. 36. 
nar sobre los individuos para obtener de ellos la conformidad de su comportamiento con ciertas reglas de conducta» ${ }^{10}$.

Ahora bien, desde las ciencias sociales se destaca que si el «objeto social fundamental» es que las conductas de las personas se ajusten a las reglas aprobadas por la sociedad organizada ${ }^{11}$, entonces el Derecho desempeña un papel relevante en garantizar que se cumpla dicho objetivo, en tanto puede obligar o incentivar, a través del establecimiento de sanciones o recompensas, la ejecución de determinados comportamientos (requiriendo al efecto la modificación de conductas desviadas) ${ }^{12}$. Dicha función tradicionalmente se ha logrado con la anudación de consecuencias desagradables frente a la realización de acciones socialmente reprochables o a la omisión de conductas socialmente deseables ${ }^{13}$, lo cual se concreta -frecuentemente- en el recurso a la coerción y, señaladamente, a las sanciones jurídicas ${ }^{14}$.

Desde esa perspectiva, el establecimiento de reglas jurídicas comporta la «reducción» o la limitación de las opciones de que disponen las personas para obrar de la manera que ellos prefieran ${ }^{15}$. Pues parte importante -cuando no todos- de nuestros comportamientos se hallan disciplinados o influenciados en alguna medida por normas jurídicas y, por lo mismo, son «obligatorios, en algún sentido» ${ }^{16}$ : tales reglas nos constrińen, por ejemplo, a conducir por un lado de la calzada o pagar impuestos o cumplir (de buena fe) los contratos que con otros suscribimos o, en su caso, las normas imponen a las empresas proveedoras de servicios determinados estándares de calidad y regularidad o la obligación de respetar los derechos de los consumidores.

Pues bien, la peculiaridad del Derecho, en cuanto instrumento de control social, reside en i) el alto grado de organización e institucionalización ${ }^{17}$ de la reacción prevista frente a un comportamiento indeseado o desviado ${ }^{18} \mathrm{y}$ ii) que, al mismo tiempo, persigue dirigir o guiar las conductas de las personas y supervigilar el funcionamiento

10 LUMIA, 1978: 13.

11 Tom TYLER, «Legitimidad y justicia penal: los beneficios de la autorregulación», en La obediencia del Derecho (estudio preliminar de Catalina PÉREZ CORREA y traducción por Carlos MORALES DE SETÉN RAVINA), Siglo del Hombre editores, Bogotá, 2014 a, pp. 107-108.

12 Vid., Tom TYLER, "La legitimidad como cuestión teórica», en La obediencia del Derecho (estudio preliminar de Catalina PÉREZ CORREA y traducción por Carlos MORALES DE SETÉN RAVINA), Siglo del Hombre editores, Bogotá, 2014 b, pp. 61-62.

13 Bien se sabe que los medios a través de los cuales se ejerce tal control son diversos y heterogéneos. "[V]an desde la negación del cariño por los padres a los hijos desobedientes, desde la desaprobación y menosprecio, hasta la marginación, el linchamiento y la pena de muerte». LUMIA, 1978:13-14.

14 Vid., Herbert L. A. HART, El concepto de Derecho (traducción por Genaro R. CARRIÓ), reim. 2. ${ }^{\text {a }}$ ed., Abeledo-Perrot, Buenos Aires, 2007, pp. 8-9.

15 Vid., Rolando TAMAYO Y SALMORÂN, El Derecho y la ciencia del Derecho, Universidad Nacional Autónoma de México, México D.F., 1984, p. 25.

16 HART, 2007: p. 7.

17 «[L]a institucionalización de la coacción, la coacción organizada es el rasgo típico del Derecho». MUÑOZ CONDE, 1985: 33.

18 LUMIA, 1978: 15-17. En ese orden, se destaca que es característica del Derecho que las reacciones críticas son sustituidas, en un alto grado, por «sanciones organizadas». Joseph RAZ, El concepto de sistema jurídico. Una introducción a la teoría del sistema jurídico (traducción, prólogo y notas por 
de las instituciones sociales (equilibrio social) ${ }^{19}$, de tal suerte que no se trata únicamente de un mecanismo de regulación, sino también de integración de la sociedad $(\text { K. Llewellyn })^{20}$.

En esa línea, es menester consignar que D. Melossi denomina como «re-activo» a «aquella modalidad de control social que afecta la motivación a través de la amenaza de negar algo que la persona a quien se amenaza considera un valor». Precisa, enseguida, que uno de los instrumentos vinculados a dicha modalidad es, sin duda, la sanción jurídica ${ }^{21}$.

En tal contexto, y habida cuenta de lo reseñado, cabe afirmar que las sanciones jurídicas constituyen un destacado medio de control social ${ }^{22}$ («re-activo»), toda vez que se asume que el «temor» a su eventual imposición influirá en que las personas decidan observar el comportamiento requerido por la norma jurídica ${ }^{23}$ (cuya exigibilidad constituye, por cierto, uno de los caracteres del Derecho en tanto sistema de control social $\left.{ }^{24}\right)$. Pues, en efecto, como ha puesto de relieve P. Navarro, «[1]a práctica de prescribir comportamientos y correlacionarlos con una sanción que tiene por función, por ejemplo, prevenir conductas, supone precisamente, que los individuos pueden motivarse a partir de las amenazas de castigo. En esta sencilla idea está el núcleo de la idea de "derecho positivo", es decir, de un derecho impuesto mediante actos específicos, del control social organizado a partir de acciones normativas» ${ }^{25}$.

En este punto, se debe mencionar que, según apunta N. Bobbio, las sanciones jurídicas se distinguirían del resto de las sanciones (morales, religiosas, sociales, etc.) por su carácter externo e institucionalizado ${ }^{26}$, de suerte que puede sostenerse que

Rolando TAMAYO Y SALMORÁN), Universidad Nacional Autónoma de México, México D.F., 1986, p. 184.

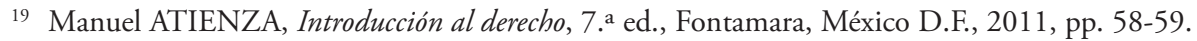
En el mismo sentido, SORIANO, 1997: 317.

20 Siguiendo K. Llewellyn, R. Rehbinder señaló que, en tanto instrumento de control social, el Derecho cumple, a lo menos dos funciones: integración o cohesión social y la «regulación del comportamiento individual». Manfred REHBINDER, Sociología del Derecho (traducción por Gregorio ROBLES MORCHÓN), Ediciones Pirámide, Madrid, 1981, pp. 87 y 160-161. Por su parte, refiriéndose a esta última, se la ha calificado como de «orientación social». Vicenzo FERRARI, Funciones del Derecho (traducción por María José AÑON ROIG y Javier DE LUCAS MARTIN), Editorial Debate, Madrid, 1989, p. 112.

21 En particular, la que ese autor denomina «negativa». MELOSSI, 1992: 205.

22 «El concepto de la sanción en la historia del pensamiento iusfilosófico es, sin duda, uno de los temas recurrentes [...] en cuanto aparece directamente vinculado a la función de ordenación u orientación de conductas o de control social, que por excelencia al derecho le corresponde». Ángela SOLANES CORELLA, «El camino de la ética a la política: la sanción en Jeremy Bentham y John Stuart Mill», en Anuario de Filosofía del Derecho, núm. 23, 2006, p. 132.

23 Vid., TYLER, 2014 a: 109-110.

24 Vid., SORIANO, 1997: 342 y ss.

25 Pablo NAVARRO, Dinámica y eficacia del derecho. Un análisis conceptual de la obediencia y aplicación del derecho, Fontomara, México D.F., 2017, p. 23.

26 De estas características se derivaría -según precisa el autor- que toda sanción jurídica i) se vincula con alguna regla primaria, ii) se relaciona con algún grado de magnitud y iii) para su aplicación, el orden 
lo que caracterizaría al Derecho sería, entonces, la configuración de un mecanismo sancionatorio ${ }^{27}$-altamente organizado e institucionalizado ${ }^{28}$, no resultando posible, así, prescindir de las sanciones jurídicas si se pretende entender de forma correcta el carácter normativo que las personas le atribuyen al fenómeno jurídico (concepción que compartiría incluso H. Hart) ${ }^{29}$.

\section{LAS SANCIONES JURÍDICAS COMO RAZONES PARA LA ACCIÓN E INSTRUMENTO QUE PERSIGUE LA EFICACIA EN EL CUMPLIMIENTO DE LAS REGLAS JURÍDICAS}

De lo hasta aquí apuntado, ¿cabe concluir que las sanciones jurídicas son las (únicas o principales) razones por las cuales las personas cumplen las reglas? Para responder dicha interrogante debe abordarse, siquiera a modo de apunte, el tema de la eficacia de tales reglas.

La visión canónica acerca de esta materia fue acuñada por $\mathrm{H}$. Kelsen, según el cual la eficacia de las reglas (que estatuyen un determinado comportamiento) consiste en que «la conducta real de los individuos se ajusta a las normas jurídicas». Tal entendimiento limitado — que califica de «única connotación» posible— trae causa, en palabras del propio autor, de la imposibilidad metodológica para determinar con «exactitud» los motivos que inducen a las personas a observar las normas jurídicas, de donde se sigue que — desde el punto de vista objetivo — únicamente se puede afirmar si la conducta de los individuos se ajusta o no a lo prescrito por la norma ${ }^{30}$.

En todo caso, precisó que la «norma sea eficaz no significa que siempre y sin excepciones sea cumplida y aplicada; significa solamente que es cumplida y aplicada en gran medida». ${ }^{31}$

Dicho concepto de eficacia, no obstante, resulta, desde luego, insuficiente y «débil» ${ }^{32}$, en tanto que no da cuenta de la necesaria vinculación de la norma con su

jurídico organiza un cuerpo de personas encargadas al efecto. De aquí se desprenden tres limitaciones de la sanción: certeza, proporcionalidad e imparcialidad. Norberto BOBBIO, Teoría General del Derecho (traducción por Eduardo ROZO ACUÑA), Editorial Debate, Madrid, 1991, pp. 124-125.

27 Vid., SORIANO, 1997: 339-340 y 354.

28 LUMIA, 1978: 17.

29 Anna PINTORE, «A Rule-Governed Gunman Writ Large? El puesto de la Coerción en "The Concept of law"», en Doxa: Cuadernos de filosofía del derecho, núm. 37, 2014, p. 139.

${ }_{30}$ Hans KELSEN, Teoría general del Derecho y del Estado (traducción por Eduardo GARCÍA MÁYNEZ), reim. 3. a ed., Universidad Nacional Autónoma de México, México D.F., 1983, pp. 27-28 y 46-47.

31 Hans KELSEN, Teoría general de las normas (traducción por Hugo Carlos DELORY JACOBS), Editorial Trillas, México D.F., 1994, p. 144.

32 «En este sentido, es usual apelar al concepto más débil de eficacia, que se refiere simplemente a la conformidad entre norma y acción, al hecho de que una norma no es desobedecida, con independencia de su incidencia en la motivación de conductas.» NAVARRO, 2017: 27. 
función motivadora ${ }^{33}$, ni logra explicar qué se entiende por cumplir el Derecho ${ }^{34}$, toda vez que, como se ha destacado por la doctrina ${ }^{35}$, la mera coincidencia entre la conducta prevista en la regla y la que acontece en la realidad, sin considerar las motivaciones concretas del obrar (supuestos en los cuales se puede aludir a correspondencia, coincidencia, conformidad o consistencia entre norma y acción ${ }^{36}$ ), no implica necesariamente que el Derecho ha operado como razón para cumplir la norma, esto es, como una razón para la acción.

Ello, por cuanto existen una serie de razones diversas a la existencia del Derecho por las cuales las normas son observadas: pues, en efecto, como se ha puesto de relieve ${ }^{37}$, las meras preferencias o gustos personales, pasando por invocaciones morales o altruistas hasta el puro autointerés, pueden constituir causas para ajustarnos al precepto respectivo. De aquí se sigue — como anota L. Hierro - que la observancia de la norma jurídica no determina, así, el grado de su «eficacia motivadora» sobre la conducta $^{38}$.

Ahora bien, en el supuesto en que la razón específica para actuar es, justamente, obedecer al Derecho y, por mismo, la existencia de la norma jurídica es un motivo para la acción, se alude al cumplimiento o acatamiento de la regla, lo que supone, como destaca J. Bayón, que «el conocimiento de que la regla existe y le es aplicable ha ejercido sobre el sujeto una influencia determinante (de algún tipo, sea meramente porque ha alterado su cálculo prudencial o porque la acepta), de manera que la inexistencia o la ignorancia de la regla habría tenido un efecto diferencial sobre su conducta» ${ }^{39}$.

33 «[E]s un error desvincular el concepto de eficacia de los sistemas normativos de la función motivadora que caracteriza a estos sistemas. La relación genérica entre eficacia y motivación no solo involucra al enunciado fáctico de la correspondencia sino también, un componente contrafáctico acerca de los cambios y acciones para el caso que no hubiese existido el sistema normativo.» Pablo NAVARRO, La eficacia del Derecho. Una investigación sobre la Existencia y Funcionamiento de los Sistemas Jurídicos, Centro de Estudios Constitucionales, Madrid, 1990, p. 56. En esa línea, Andrea GREPPI, «Eficacia», en Euronomía. Revista en cultura de la Legalidad, núm. 3, 2012, p. 153. (Accesible https://e-revistas.uc3m. es/index.php/EUNOM/article/view/2126/1057).

34 Esta línea de investigación nos puede llevar muy lejos, a la pregunta de por qué las personas obedecen el Derecho, cuestión que escapa con mucho el objeto del presente estudio. Para profundizar en este aspecto, vid. Frederick SCHAUER, Fuerza de Ley (traducción y estudio preliminar por Pablo Ariel RAPETTI,), Palestra editores, Lima, 2015, pp. 153 y ss.

35 Cfr. Liborio HIERRO, La eficacia de las normas jurídicas, Ariel, Barcelona, 2003, p. 75, y SCHAUER, 2015: 155 y ss.

36 "La eficacia del derecho se asocia a una "familia" de conceptos referidos a diversas relaciones entre norma y conducta. "Una" de estas relaciones es la que se articula en torno a diferentes formas de "observancia o correspondencia". En casos en que una norma es eficaz, la conducta se corresponde con la exigencia de la norma jurídica. Ahora bien: ¿qué tipo de conexión es relevante? Una respuesta mínima, consiste en la "mera conformidad" entre exigencia y conducta.» NAVARRO, 2017: 22.

37 Cfr. SCHAUER, 2015: 157 y 164.

38 HIERRO, 2003: 81 y 130.

39 Juan Carlos BAYÓN, La normatividad del Derecho: deber jurídico y razones para la acción, Centro de Estudios Constitucionales, Madrid, 1991, p. 460, nota 299. 
De suerte que, así entendido, todo cumplimiento constituye i) un supuesto de correspondencia, "pero no a la inversa" ${ }^{40}$, esto es, no toda correspondencia significa cumplimiento de la regla y ii) un indicador de eficacia motivadora del precepto o de la normativa específica de que se trate ${ }^{41}$.

En tal orden de ideas, cabe distinguir con L. Hierro entre la eficacia como capacidad de las normas para producir efectos jurídicos (por haberse satisfecho las condiciones para ello ${ }^{42}$ y la eficacia como capacidad para motivar un determinado comportamiento por sus destinatarios y, en caso de inobservancia, la atribución de una consecuencia jurídica (vale decir, al cumplimiento de la norma por sus destinatarios y, ante su infracción, la aplicación de esta $)^{43}$.

En este segundo sentido, como bien pone de relieve este autor, la obediencia de la norma se verifica, entre otras razones, por motivos prudenciales, bien porque el cumplimiento de las normas por el agente le es útil a sus intereses o bien para evitar sufrir el coste de la sanción que su incumplimiento le podría reportar ${ }^{44}$. Este aspecto resulta relevante, pues como notó $\mathrm{J}$. Raz ${ }^{45}$, la mera existencia de un precepto respaldado por una sanción es una «razón parcial auxiliar» para la acción: para ser una "completa» (o como el autor la llama «razón operativa») se requiere que el agente pretenda, justamente, evitar la sanción a través del respeto a la regla ${ }^{46}$.

Siendo así, cabe afirmar que, en términos generales, las sanciones jurídicas tienen la virtualidad de contribuir a la eficacia de la norma, en tanto tienen la capacidad de disuadir la infracción a la misma y, por lo tanto, constituyen una de las razones por las cuales se cumple con las reglas. «Las sanciones que el Derecho prevé aplicar a quienes incumplen sus normas tienen la finalidad primordial de fomentar la eficacia del Derecho, disuadiendo del incumplimiento» ${ }^{47}$.

Consecuente con ello, aparece que las sanciones jurídicas son dispositivos que operan como razón para la acción, esto es, son uno de los motivos que los agentes colocan en la —utilizando una expresión de J. Raz- «balanza de razones» ${ }^{48}$, al momento de decidir si ajustar o no su conducta a la normativa de que se trate ${ }^{49}$.

40 BAYÓN, 1991: 460.

41 HIERRO, 2003: 130.

42 En tal sentido, como pone de relieve el autor, la eficacia de la norma es muy parecida o equivale a su validez.

43 HIERRO, 2003: 71-73. En este trabajo se utilizará en el segundo sentido.

44 HIERRO, 2003: 95.

45 RAZ, 1991: 187.

46 Nótese que otros autores ponen de relieve que el motivo para actuar no es la norma «sino el miedo al castigo o el deseo al premio asociados con la norma». NAVARRO, 1990: 89.

47 FERNÁNDEZ-GALIANO y DE CASTRO CID, 1994: 281.

48 Joseph RAZ, La autoridad del derecho. Ensayos sobre el derecho y la moral (traducción y notas por Rolando TAMAYO Y SALMORÁN), 2. ${ }^{a}$ ed., Universidad Nacional Autónoma de México, México D.F., 1985 , p. 17.

49 En este punto, deben formularse sí dos precisiones: 1) que el sujeto considere la existencia de la norma como una razón para actuar es una cuestión que puede suceder o no (es más, puede que su acción coincida con lo prescrito con la norma) y 2) la determinación del motivo específico para actuar es una 
Aún más, la técnica de las sanciones jurídicas tiene una relevancia especial en dicha balanza, pues, sobre la imagen de que las personas no son ángeles ni demonios (H. Hart), cabe afirmar con D'Agostino ${ }^{50}$ que las sanciones constituyen una garantía "de vital importancia», en tanto no puede concebirse el fenómeno jurídico sin dicho instrumento, por dos razones decisivas: 1) debido a que implícita en la regla se halla la posibilidad de que ella sea infringida (de otro modo, no es regla, "es un hecho»), de suerte que, en ausencia de una especifica respuesta, difícilmente podría definirse como Derecho y 2) en tanto el Derecho garantiza la «coexistencia social», supone que existen ciertos principios jurídicos aceptados, que se aseguran, justamente, por el orden jurídico, a través de tales respuestas.

Con todo, es menester destacar que del hecho que el temor a las sanciones opere como una de las razones para la acción, no se sigue, por cierto, que ellas sean (como se suele entender) ni el principal, ni mucho menos el único motivo por el cual las reglas son obedecidas ${ }^{51}$. Esta frecuente asunción - como pone de relieve L. Hierro $^{52}$ - se afinca en tres paradigmas: 1) uno jurídico, el positivismo (cuyo principal representante es Kelsen); 2) uno sociológico, el modelo racional-formal (diseñado por M. Weber); y, 3) uno económico, la Teoría de la Elección Racional —TER— (en la que se destacan los autores utilitaristas).

Tal asunción ha sido cuestionada por estudios provenientes de la psicología ${ }^{53}$ y de parte de la doctrina jurídica ${ }^{54}$ pues, en efecto, además de la amenaza de sanción, factores tales como la interiorización de los mandatos jurídicos y la legitimidad de la autoridad del cual emanan son, entre otros, elementos relevantes en la decisión de sujetarse a las reglas pertinentes. Por lo mismo, se ha advertido que el acatamiento de la regla no obedece al simple esquema coste/beneficio, sino que responde a una diversidad de factores complejos $\mathrm{y}$ «de diferente relieve según el tipo de conducta, el tipo de destinatario y el tipo de sanción» ${ }^{55}$.

En ese contexto, cabe compartir con A. Greppi que efectivamente la «fuerza regulativa del Derecho ya no depende solo de su capacidad para orientar por sus propias

"cuestión empírica»y, por tanto, "puede fallarse — como ocurre a menudo - en determinar si cierto sujeto ejecuta una acción por tal o cual motivo». NAVARRO, 1990: 90 y 92.

50 Francesco D’AGOSTINO, Filosofía del derecho (traducción por José RODRÍGUEZ ITURBE), Editorial Temis, Bogotá, 2007, p. 141.

51 HIERRO, 2003: 101-102.

52 HIERRO, 2003: 99-102.

53 Vid., TYLER, 2014 b: 57 y ss.

54 «El miedo al castigo no necesita ser el único motivo para la obediencia de la norma. Puede incluso considerarse como esencial para algunos tipos de prescripciones, las leyes del estado, por ejemplo, que haya otros motivos además del miedo para obedecerlas. Es a lo mejor cierto que normalmente, cuando la acción se ajusta a las prescripciones, el motivo no es el miedo al castigo o a otras consecuencias desagradables. La función de la sanción es constituir motivo de obediencia de la norma en ausencia de otros motivos de obediencia y en presencia de motivos de desobediencia. Cuando el sujeto está tentado de desobedecer, el miedo al castigo es una de las cosas que pueden "llamarle al orden". En casos extremos, es la única cosa que puede conseguirlo.» G. Henrik VON WRIGHT, Norma y acción. Una investigación lógica (traducción por Pedro GARCÍA FERRERO), Tecnos, Madrid, 1979, p. 139.

55 HIERRO, 2003: 100-105. 
fuerzas la conducta de sus destinatarios, recurriendo típicamente al monopolio de la coacción ejercida por un agente dotado de autoridad»: se requiere, añade, tener presente otros aspectos como la gradualidad i) de la exigencia de obligatoriedad en el cumplimiento de las normas, ii) de la precisión de los enunciados normativos de las reglas (y, por lo mismo, la variabilidad en la discrecionalidad de la autoridad encargada de aplicarlas), y iii) en los niveles de delegación en terceros en «las operaciones de interpretación, supervisión o implementación» ${ }^{56}$.

Consecuente con lo expuesto, cabe concluir que, si bien el uso de las sanciones es una de las técnicas relevantes a través de las cuales los sistemas jurídicos aspiran a lograr su eficacia, tal instrumento no siempre se utiliza ${ }^{57}$, ni es el único que se articula en función a la consecución de dicho fin.

\section{LA FORMA TRADICIONAL DE ARTÍCULACIÓN DEL CONCEPTO DE SANCIÓN JURÍDICA}

Establecido lo anterior, debe precisarse que cuando se afirma que el Derecho es un sistema de control social se alude principalmente (cuando no, exclusivamente) a los delitos y las sanciones penales —esto es, las penas — ${ }^{58}$. Recuérdese, en este orden - como destaca N. Bobbio-, que desde C. Thomasius (siglos XVII y XVIII) se consideró que el objeto del Derecho no era más que la protección de las actuaciones lícitas, a través de la represión de los actos ilícitos, para cuyo efecto se fijaba un conjunto de prohibiciones, con lo cual se fue construyendo una visión eminentemente represiva del orden jurídico, que se identificó con el Derecho penal ${ }^{59}$.

Dicha concepción se reforzó con el entendimiento tradicional del Estado liberal clásico, en cuya construcción la actividad administrativa era relativamente escasa (y, por tanto, secundaria), de modo que se podía «prescindir de un Derecho penal administrativo» ${ }^{60}$, en tanto que el papel central del modelo era el de guardián del orden público (articulado sobre la base de normas negativas) ${ }^{61}$, en el que bastaba el Derecho criminal para sancionar las perturbaciones a aquel.

Tal predicamento, desde el punto de vista histórico, trae causa, en último término, de que al surgir el Derecho penal de policía (que, en términos generales, hoy sería equivalente, en parte, al actual Derecho administrativo sancionador), durante el período del Estado absolutista, no existió diferencia material entre este y Derecho

56 GREPPI, 2012: 157-158.

57 Brenner M. FISSELL, "Sanctions and Efficacy in Analytic Jurisprudence», en Rutgers Law Review, Vol. 69, 2017, pp. 1628 y 1638.

58 Por razón de que, de un lado, es la doctrina penal la que ha analizado en mayor profundidad el control social —Cfr. ATIENZA, 2011: 61-62 - y, por otro, es la pena el principal elemento de coacción jurídica -MUÑOZ CONDE, 1985: 33-.

59 BOBBIO, 1990: 372-374.

60 Reinhart MAURACH, Tratado de Derecho penal. Vol. I (traducción y notas por Juan CÓRDOVA RODA), Ariel, Barcelona, 1962, pp. 16-17.

61 Cfr. BOBBIO, 1990: 372-374. 
penal criminal y, por lo mismo, se identificaban como penales las sanciones provenientes de ambos órdenes jurídicos ${ }^{62}$. Únicamente, en forma posterior, con el advenimiento del liberalismo, se comenzaron a formular las primeras teorías que pretendian distinguir entre ilícito penal e ilícito administrativo ${ }^{63}$, las cuales fueron perfeccionadas y desarrolladas por la doctrina alemana, dando lugar a la distinción entre el Derecho penal propiamente tal y el Derecho penal administrativo (destacadamente, J. Goldschmidt, E. Wolf y Eb. Schmidt $)^{64}$.

No obstante, la mencionada concepción represiva-penal de las sanciones jurídicas sobrevivió, en lo sustancial, al transcurso de los años, a pesar de los cambios de paradigmas sociales y culturales y de la sustitución de diversos regímenes políticos o modelos (por ejemplo, la instauración del Estado social) ${ }^{65}$, con lo cual se fue condicionando -incluso hasta nuestros días- la configuración y el entendimiento de dichas sanciones, en cuanto a que estas se fueron articulando a partir de, y en función a, la teoría y dogmática del Derecho penal ${ }^{66}$ (a pesar de ser este, en el contexto del control social, una instancia más bien secundaria ${ }^{67}$ ).

${ }^{62}$ En tal sentido, tras un profundo estudio de la evolución histórica del Derecho penal en Alemania, H. Mattes concluye que no existía «desde el punto de vista jurídico material una diferencia histórica entre Derecho penal de policía y Derecho penal criminal o judicial (infracciones administrativas e injusto criminal). El Derecho penal de policía [que, en términos generales, hoy sería el equivalente al Derecho administrativo sancionador], nacido con el Estado absoluto en la Edad Moderna, era un Derecho penal de los órganos (administrativos) de policía y no estaba separado del resto del Derecho penal por caracteres materiales, de índole diferencial.» Heinz MATTES, Problemas de Derecho Penal Administrativo. Historia y Derecho Comparado (traducción por José María RODRÍGUEZ DEVESA,), Edersa, Madrid, 1979, pp. 138-139.

63 Singularmente, con P. Feuerbach, a partir de lo que él denominaba el delito contra el Derecho y el mero delito de policía, con el fin de evitar la hipertrofia del Derecho penal producida por la excesiva carga de los tribunales. José CEREZO MIR, «Limites entre el Derecho penal y el Derecho administrativo", en Anuario de derecho penal y ciencias penales, Tomo XXVIII, Fascículo II, 1975, p. 161.

${ }^{64}$ Es menester recordar que intentos dogmáticos por distinguir ontológicamente penas judiciales de las sanciones administrativas han sido notables, tanto por la diversidad, como por la cantidad de los mismos (señaladamente, en la doctrina alemana e italiana), los que, no obstante, han sido abandonados por infructuosos. Sobre esta materia nos remitimos al riguroso estudio efectuado por Alejandro HUERGO LORA, Las sanciones administrativas, Iustel, Madrid, 2007, pp. 53 y ss., y, del mismo autor, «Diferencias de régimen jurídico entre las penas y las sanciones administrativas que pueden y deben orientar su utilización por el legislador, con especial referencia a los instrumentos para la obtención de pruebas», en HUERGO LORA, Alejandro (dir.) Problemas actuales del Derecho administrativo sancionador, Iustel, Madrid, 2018, pp. 15 y ss., como también son interesantes MATTES, 1979: 177 y ss., y CEREZO MIR, 1975: 161 y ss.

${ }^{65}$ En cuya virtud la Administración asumió una enorme cantidad de actividades (y consecuentemente, se produjo un aumento de las funciones estatales), lo que tornó imprescindible la atribución a esta de potestades sancionadoras, requiriéndose, con ello, nuevas explicaciones teórico-dogmáticas para la construcción, primero, de un «Derecho penal administrativo» y, posteriormente, un «Derecho administrativo sancionador». MAURACH, 1962: 16-18.

${ }_{66}$ Pues, de un lado, es la doctrina penal la que ha analizado en mayor profundidad el control social -Cfr. ATIENZA, 2011: 61-62-y, por otro, es la pena el principal elemento de coacción jurídica -MUNOOZ CONDE, 1985: 33-.

${ }^{67}$ En tanto, como anota Muńoz Conde, se trata de un instrumento confirmador y asegurador de otras instancias de control social mucho más eficaces, que no crea valores ni constituye un sistema autó- 
La anotada concepción se vio reforzada por el lastre histórico de sistemática desconfianza hacia la Administración pública por parte de la doctrina y jurisprudencia (que concebía a la Administración como una organización dotada de facultades exorbitantes, ejercidas en forma arbitraria — señaladamente, la potestad sancionadora-, sin sujeción a técnicas que las racionalicen), con lo cual, a pesar del cambio de los sistemas políticos, se fue restringiendo la configuración y el ejercicio de la actividad de aquella; desde esta óptica, se entiende la permanente necesidad de invocación de garantías y principios propios de otros órdenes normativos (como el Derecho penal), a fin de limitar, cuando no excluir, cualquier posibilidad de discrecionalidad en el desarrollo de la acción administrativa.

Prueba de que la construcción teórico-jurídica de las sanciones se realizó desde la lógica del Derecho penal cabe encontrarla en que i) parte importante de la literatura especializada no distingue entre diversos tipos de sanciones, bien limitándose a identificar estas con las penas o el castigo ${ }^{68}$, bien utilizando el concepto pena como género - y no como especie ${ }^{69}$-, bien, por fin, definiendo tipos de sanciones jurídicas diversas a las criminales como penas (eje., afirmando que la sanción administrativa es una forma de pena $a^{70}$ ) y ii) los textos legales del siglo XIx (construidos sobre la base del liberalismo clásico) calificasen como pena a las que entendían como sanciones civiles (así, los arts. 204, 400, 1301, 1407, etc., del Código Civil Chileno atribuyen a la nulidad el carácter de pena).

nomo de motivación del obrar de las personas. Se diferencia más bien por contener un «plus adicional en intensidad y gravedad de las sanciones y en el grado de formalización que su imposición y ejecución exige.» Pero ni es «el único, ni el más importante» de los mecanismos de control social. MUÑOZ CONDE, 1985: 37.

${ }_{68}$ Así, se afirma que "[e]l concepto de sanción que la teoría del derecho contemporánea utiliza procede mediatamente de Bentham y de Austin, y se elabora en diálogo crítico con los planteamientos de Kelsen. Sanción es equivalente a pena o castigo». Jesús DELGADO ECHEVERRÍA, Validez de normas y de actos jurídicos. Estudios de Teoría General desde el derecho privado, Marcial Pons, Madrid, 2019, p. 187. La cursiva es nuestra.

69 «Las penas reservadas al Derecho penal se denominan penas criminales [...] La pena criminal se distingue, tanto en sus presupuestos como en su esencia, de las penas o de las intervenciones similares a la pena». Reinhart MAURACH, Derecho penal. Vol. 1: Teoría general del Derecho penal y estructura del hecho punible (versión actualizada por Heinz ZIPF, y traducida de la 7. ${ }^{a}$ ed. alemana por Jorge BOFILL GENZSCH, y Enrique AIMONE GIBSON), Astrea, Buenos Aires, 1994, p. 8.

${ }^{70}$ La sanción administrativa es una "pena en un sentido técnico, cuya aplicación constituye, para la Administración, a la que se refieren los deberes que sanciona, un derecho subjetivo» o un «acto punitivo», esto es, «las penas que son aplicables por vía administrativa, es decir las diversas sanciones (disciplinarias, fiscales, etc.) que la administración puede infligir por su propia autoridad, por inobservancia de deberes hacia la misma.» Guido ZANOBINI, Le sanzioni amministrative, Fratelli Boca, Torino, 1924, pp. 38 y ss., y, del mismo autor, Curso de Derecho administrativo. Vol. I. Parte General (traducción por Héctor MASNATTA, y actualizada por Francisco Humberto PICONE), Ediciones Arayú, Buenos Aires, 1994, p. 338; respectivamente. 


\subsection{El corolario de esta forma de construcción: la asunción de un ius puniendi (derecho a castigar) único del Estado}

La apuntada construcción de la noción de sanción resulta relevante por diversos motivos; específicamente, en lo que aquí interesa, por razón de que entre el Derecho administrativo y el Derecho penal existen continuas relaciones e interacciones, las que han suscitado - desde el nacimiento del primero a consecuencia de la Revolución francesa- controversias de profundo calado, particularmente, en sus zonas de contacto (en que la frontera entre uno y otro tiende a la volatilización).

La permanente dialéctica entre la exigencia de eficacia en el cumplimiento de la actividad administrativa y las mayores garantías que el orden penal otorga a los ciudadanos es una cuestión que plantea a los poderes públicos — señaladamente, al legislador- desafíos de gran porte: en especial, cuando estos (con miras a la consecución de sus objetivos — p. ej. la seguridad ciudadana y el orden público-), previa ponderación de los derechos y bienes involucrados, determinan, de un lado, recurrir a uno u otro ordenamiento y, del otro, disciplinar sus interacciones recíprocas.

Pues bien, uno de los ámbitos en que con mayor intensidad se advierte dicha tensión es, justamente, el Derecho administrativo sancionador, caracterizado por la doctrina, incluso y por tal motivo, como "mestizo» ${ }^{11}$ - mezcla de Derecho penal y Derecho administrativo-.

Como consecuencia de la forma de afrontar el estudio de las sanciones jurídicas - a partir de la lógica y funciones propias del Derecho penal — no resulta extraño que se hubiese asumido por diversos tribunales la teoría de un ius puniendi (derecho a castigar) único del Estado, cuyas manifestaciones estarían constituidas por el Derecho penal y el Derecho administrativo sancionador y, por tanto, siendo ambas expresiones del mismo ordenamiento punitivo, procede aplicar, con ciertos matices, los principios inspiradores del primero al segundo ${ }^{72}$.

La articulación, límites y consecuencias de tales «matices» — los cuales, con el tiempo, han crecido tanto en cantidad como en intensidad - han concentrado los estudios dogmáticos de los especialistas ${ }^{73}$, con descuido de otras cuestiones previas, como el fundamento teórico y normativo de tal construcción - el cual se da por supuesto, sin analizar, además, el origen de su comprensión actual—, como asimismo, su (des)ajuste al Estado Constitucional o la acusada necesidad de depuración de

71 Vid., Luciano PAREJO ALFONSO, "Algunas reflexiones sobre la necesidad de depuración del status de la sanción administrativa», en Revista General de Derecho Administrativo, núm. 36, 2014 , p. 8. Por su parte, Huergo Lora califica a las sanciones administrativas como de "una posición intermedia» entre el Derecho penal y el administrativo, añadiendo, además, que se trata de un «injerto penal en una planta administrativa, de un cuerpo extraño, en suma.» Alejandro HUERGO LORA, "Ponencia sobre Derecho penal y administrativo", en II Seminario de Teoría y Método del Derecho Público, celebrado en la Universidad Autónoma de Madrid, Madrid, 29 de noviembre de 2013, 2013, p. 2.

72 STC Roles 244, 479, 1518, 2264, 2946 y, últimamente, 3236-16, de fecha 24 de mayo de 2018.

73 Salvo notables excepciones, como destacadamente Alejandro NIETO GARCÍA, Derecho administrativo sancionador, 5. ${ }^{\mathrm{a}}$ ed., Tecnos, Madrid, 2012. 
la configuración de la potestad administrativa sancionadora (singularmente, su impronta jurídico-administrativa y, por lo mismo, su carácter de instrumento destinado a la satisfacción del interés general).

De aquí, pues, que por regla general, la doctrina no haya cuestionado i) el sustento teórico y normativo de tal tesis (antes al contrario, se advierte que dicho planteamiento constituye el presupuesto de toda elaboración argumentativa posterior) y ii) una de las principales consecuencias de ella: las potestades penal judicial y administrativa sancionadora persiguen, en esencia, el mismo objetivo punitivo (identidad punitiva o de castigo).

Y es que, paradójicamente, a pesar de ser el Derecho administrativo sancionador uno de los ámbitos que mayor dedicación ha merecido de parte de la doctrina, al mismo tiempo, es uno de los que más requiere de una construcción que, a partir de la teoría jurídica y sobre la base del orden jurídico vigente, le dé una explicación satisfactoria.

\subsection{Progresiva "penalización del Derecho administrativo" y de «administrativización del Derecho penal»}

La apuntada necesidad de (re)construcción de la potestad sancionadora de la Administración se ha convertido, en estos últimos años, en una cuestión aún más acuciante por razón de la progresiva tendencia a la utilización del Derecho como mecanismo para lograr la efectividad de las políticas y programas legales y, por tanto, los resultados pretendidos (p. eje., la tutela del consumidor, la salud, las prestaciones sociales, o, en general, el funcionamiento de los sectores regulados, etc.), para cuya concreción se ha recurrido a criterios —eficiencia, eficacia, aceptabilidad o, en fin, optimización-, métodos o técnicas que, en muchas ocasiones, no solo son diversos a los que tradicionalmente se emplea por la rama del Derecho de que se trate, sino que, incluso, pueden trastocar o poner en entredicho la posición y funciones ordinamentales de la misma.

Manifestación clara de lo reseñado son, desde luego, los fenómenos denominados por la doctrina ${ }^{74}$ como "penalización del Derecho administrativo» y de «administrativización del Derecho penal»; así, p. eje., la expansión del Derecho penal conduce, como anota Silva Sánchez, a la conversión de este en un instrumento de "gestión ordinaria de los grandes problemas sociales» ${ }^{75}$, en virtud del cual, incluso, se alude a su consideración como "prima o sola ratio» ${ }^{76}$.

74 Por todos, vid., Jesús SILVA SÁNCHEZ, La expansión del Derecho Penal. Aspectos de la Política criminal en las sociedades posindustriales, 2. ${ }^{\mathrm{a}}$ ed., revisada y ampliada, Civitas, Madrid, 2001, pp. $121 \mathrm{y}$ ss., y Santiago MUÑZ MACHADO, Tratado de Derecho Administrativo y Derecho Público General, Vol. 1, 2. a ed., Iustel, Madrid, 2006, pp. 77 y ss.

75 SILVA SÁNCHEZ, 2001: 130.

76 Bernardo FEIJOO SÁNCHEZ, "Sobre la "Administrativización” del Derecho penal en la "Sociedad del Riesgo"", en AAVV, Derecho y justicia penal en el siglo XXI: Liber amicorum en homenaje al profesor Antonio González-Cuéllar García, editorial Constitución y Leyes, Madrid, 2006, p. 138. 
En forma telegráfica, siguiendo a la doctrina, el proceso de «administrativización» del orden penal se expresa en la i) creación de tipos penales para ámbitos tradicionalmente ocupados por el Derecho administrativo y ii) atribución a la pena de una nueva función consistente en ser «instrumento de gestión de la delincuencia como "macroriesgo" social»" ${ }^{77}$. En suma, «la utilización de la pena al servicio de la efectividad de normas de comportamiento con sede en el Derecho administrativo o, incluso, sustituyendo a este en su función propia» ${ }^{78}$.

Esta última situación — progresiva utilización de la pena judicial para la consecución de fines ajenos a la misma, como la "expulsión de extranjeros»" ${ }^{79}$, en fin, meramente administrativos - trae causa, entre otros motivos, de la insuficiencia del instrumental clásico del Estado social y democrático de Derecho para hacer frente a los peligros y riesgos de las sociedades modernas, en términos que la normal tensión libertad-seguridad se ha desbalanceado a favor de esta última ${ }^{80}$ : como expresa Parejo Alfonso, se ha producido un traslado del centro de gravedad del Estado social y democrático de Derecho hacia la «prevención» y, por tanto, a la garantía de la seguridad (Präventionsstaat), con todas las consecuencias que ello comporta ${ }^{81}$.

\section{LA EMERGENCIA DE LA OBJECIÓN DEL IUS PUNIENDI ÚNICO Y LA ARTICULACIÓN DE LAS SANCIONES JURÍDICAS DESDE LA TEORÍA GENERAL}

Siendo ello así, es menester ahora avanzar y cuestionar los fundamentos de la tesis que asume que la potestad sancionadora de la Administración es, junto con la penal judicial, una manifestación del ius puniendi (concebido como el derecho a castigar) único del Estado, poniendo de relieve la precariedad de su sustento teórico y normativo (singularmente, debido a la inadecuada concepción unitaria respecto de dos potestades que, al menos, son funcionalmente diversas).

77 FEIJOO SÁNCHEZ, 2006: 1391.

78 Luciano PAREJO ALFONSO, «La deriva de las relaciones entre los derechos administrativos y penal. Algunas reflexiones sobre la necesaria recuperación de su lógica sistemática», en Revista de Documentación Administrativa, núms. 284-285, 2009, p. 278. (La cursiva es del original).

79 Fernando NAVARRO CARDOSO, «Expulsión "penal” de extranjeros: una simbiosis de Derecho penal "simbólico" y Derecho penal del "enemigo"”, en Revista de Derecho Penal y Criminología, 2.a Época, núm. 17, 2006, pp. 153 y ss.

80 En tal sentido, Wolfgang HOFFMANN-RIEM, «Libertad y Seguridad en la estela de los atentados terroristas», en Revista Teoría y Realidad constitucional, núms. 12-13, 2003, pp. 476 y ss.

81 Luciano PAREJO ALFONSO, Transformación y ireforma? del Derecho Administrativo en España, Instituto Nacional de Administración Pública y Global Law Press, Sevilla, 2012 a, pp. 25-26 y, con el mismo título, en BARNES, Javier (ed.), Innovación y Reforma en el Derecho Administrativo, 2. a ed., Instituto Nacional de Administración Pública y Global Law Press, Sevilla, 2012 b, p. 391. 
Desde el punto vista del Derecho positivo, en todo caso, baste por de pronto puntualizar que - como anota Parejo Alfonso- lo determinante en un orden constitucional vigente es i) el carácter constituido de los poderes públicos y su división constitucional y ii) la disposición completa de los mismos al servicio del orden constitucional sustantivo, y su articulación en función de dicho valor; desde esta perspectiva, los poderes públicos operan como instrumentos para la ejecución permanente del orden constitucional a partir de la división funcional básica ${ }^{82}$.

De aquí, pues, que la configuración de las potestades provenga directamente de la norma constitucional, y no de una cuestionada construcción histórico-dogmática ${ }^{83}$; así, en la actualidad no resulta procedente que se afirme la existencia de un (supuesto) ius puniendi, derecho del Estado a castigar —que más bien constituye un lastre histórico expresivo de ideas pretéritas y metafísicas ya superadas ${ }^{84}$ -

En tal contexto, cabe dejar establecido que la aún vigente Constitución Política chilena ${ }^{85}$ no consagra normativamente el ius puniendi único del Estado, entendido en los términos apuntados, ni se desprende de su preceptiva, razón por la cual la construcción de dicho predicamento carece de fundamento jurídico positivo: de allí

82 PAREJO ALFONSO, 2014: 19-20.

83 Desde el punto de vista histórico, tal como ha destacado la doctrina, el entendimiento del ius puniendi como derecho a castigar del Estado trae causa, en último término, de la confusión de poderes en el régimen monárquico absoluto, en el que el Rey ejercía diversas facultades (incluidas las que hoy denominamos potestad administrativa sancionadora) y, singularmente, se enmarca dentro de la particular historia de la evolución del Derecho público alemán (en cuya construcción destacan los grandes juristas alemanes del siglo xix, como F.J. Stahl, K. F. W. von Gerber, P. Laband y G. Jellinek), basada en el principio monárquico, cuya finalidad era la juridificación del Estado mediante la atribución de personalidad (y, por tanto, su consideración como sujeto de derecho) y su capacidad de autolimitación (al someterse al ordenamiento jurídico), predicamento que se anuda a la teoría de los derechos públicos subjetivos: se entiende, así, que el Estado pueda ser titular de derechos públicos subjetivos, entre ellos, del derecho a castigar, vale decir, del ius puniendi.

De aquí, entonces, que puede concluirse que en la comprensión tradicional del ius puniendi han operado elementos históricos, vinculados a la articulación durante el siglo xIx por la doctrina alemana de las reseñadas teorías de la personalidad del Estado y de los derechos públicos subjetivos. Celia SUAY HERNÁNDEZ, "Refutación del ius puniendi», en Luis ARROYO ZAPATERO y Ignacio BERDUGO GÓMEZ DE LA TORRE (coords.), Homenaje al Dr. Marino Barbero Santos: in memorian, Universidad de Castilla-La Mancha y Universidad de Salamanca, vol. I, 2001, pp. 712 y ss., y PAREJO ALFONSO, 2014: 12 .

84 Pues, en efecto, como consignó Novoa Monreal, el ius puniendi i) se concibe como un mero postulado ideológico, expresivo de ideas de épocas pretéritas y metafísicas (propias de Estados organizados conforme a predicamentos filosófico-políticos ya superados, como el Estado feudal, monárquico e, incluso, el Estado burgués) y ii) por lo mismo, no encuentra recepción en el Derecho penal científico. Eduardo NOVOA MONREAL, "Algunas reflexiones sobre el Derecho de Castigar del Estado», en Anuario de Filosofía del Derecho, Tomo I, 1984, pp. 202 y 211, y, con el mismo título, en Roberto BERGALLI y Juan BUSTOS (directores y compiladores), El Poder Penal del Estado. Homenaje a Hilde Kaufmann, Depalma, Buenos Aires, 1985, pp. 192, 202-203.

85 Existen ya posturas que abogan por que en la posible nueva Constitución se reconozca expresamente la potestad sancionadora de la Administración: vid., Rosa Fernanda GÓMEZ, "Potestad sancionadora de la Administración: la conveniencia de su reconocimiento constitucional», en Revista de Derecho Administrativo Económico, núm. 32, 2020, pp. 37 y ss. 
que las sentencias que conciben al ius puniendi como un derecho a castigar o un derecho subjetivo a castigar del Estado ${ }^{86} \mathrm{y}$, en su caso, a las sanciones administrativas como manifestación de esa tesis ${ }^{87}$, no tienen recepción en el vigente texto constitucional ni, en todo caso, se ajustan al régimen democrático y constitucional (art. 19, inc. 6, CP).

Tras objetar, así, la asunción del ius puniendi único como explicación y justificación normativa de la potestad sancionadora de la Administración, resulta imperativo examinar la posibilidad de una (re)construcción de la noción de sanción administrativa, a partir de la teoría general del Derecho ${ }^{88}$. Pues, en efecto, un análisis correcto y fructífero de la figura en estudio exige insertarla en el contexto más amplio de las sanciones jurídicas, en tanto se trata de una especie - como, asimismo, la pena judicial ${ }^{89}-\mathrm{y}$, por tanto, su entendimiento y configuración teórico-dogmática deben realizarse, previamente, desde la teoría jurídica.

En dicho marco, cabe consignar que la doctrina tradicional (p. eje., la ius administrativa) no ha extraído de la afirmación de que la pena judicial es solo una especie de sanción jurídica todas las consecuencias que de ella derivan, como la necesaria construcción de una teoría general propia de las sanciones jurídicas (aplicable, por cierto, a las sanciones administrativas) ${ }^{90} \mathrm{y}$, por tanto, no necesariamente dependiente ni subordinada al Derecho penal.

La explicación de ello puede radicar, en parte, en la constante disociación (cuando no divorcio) entre la teoría general del Derecho y las particulares disciplinas jurídicas - que, generalmente, demuestran escaso interés por las aportaciones de aquella-. Tal visión, junto con dificultar las naturales relaciones e interacciones que entre aquellas deben producirse, olvida que, en muchas ocasiones, para entender la configuración, aplicación y resolución de un asunto, procede acudir a la teoría jurídica, toda vez que, justamente, una de las funciones de esta es que «permite la clasificación

86 «El ius puniendi consiste en el derecho subjetivo del Estado de castigar que tiene el Estado conforme a la Constitución y a la ley.» Prevención del ministro seńor Nelson Pozo, en la STC 1048-17, de fecha 7 de mayo de 2018, FJ 5.

87 STC Roles 244, 479, 1518, 2264, 2946 y, últimamente, 3236-16, de fecha 24 de mayo de 2018.

88 El recurso a la teoría derecho, esto es, la aplicación de conceptos y estructuras diseñados por dicha disciplina, al examen de las sanciones administrativas reside también en que se trata de un "problema relevante», en los términos que puntualiza M. Atienza; vale decir: a) tiene indudable repercusión en la práctica jurídica; b) incide en valores o principios constitucionales, como el de principio de legalidad, la interdicción de la arbitrariedad o satisfacción del interés general; y, c) se trata de una cuestión que - hasta el día de hoy - es arduamente debatida tanto en la doctrina, como en la jurisprudencia, sin que existe una respuesta definitiva de su caracterización. Vid., Manuel ATIENZA RODRÍGUEZ, "Diez consejos para escribir un buen trabajo de dogmática», en Isonomía: Revista de Teoría y Filosofía del Derecho, núm. 3, 1995, pp. 223-224.

89 "La pena es solo una especie de sanción». Carlos Santiago NINO, Introducción al análisis del Derecho, 2. ${ }^{\mathrm{a}}$ ed., ampliada y revisada (12. ${ }^{\mathrm{a}}$ reimp.) Ariel, Barcelona, 2003, p. 172.

${ }_{90}$ Un reciente e interesante trabajo en el que se aborda — sucintamente- la necesidad (o no) de la construcción de una teoría general de las sanciones administrativas en Raúl LETELIER, «Sanciones administrativas regulatorias: tres premisas sobre su función», en Revista de Derecho Administrativo Económico, núm. 32, 2020, pp. 65 y ss. 
conceptual y/o dogmática de la correspondiente solución del problema, [y] asegura su compatibilidad con el sistema del Derecho vigente» ${ }^{91}$.

Por ello, no puede sino compartirse con E. Casetta que el Derecho positivo únicamente presupone ciertos conceptos de ilícito y de sanción administrativa, los cuales deben ser construidos e identificados desde la teoría general del Derecho ${ }^{92}$.

\section{LA IMPORTANCIA DE LA DEBIDA ARTÍCULACION DE LAS SANCIONES ADMINISTRATIVAS: SU CARÁCTER DE INSTRUMENTO QUE PERSIGUE LA CONSECUCIÓN DE POLÍTICAS Y PROGRAMAS NORMATIVOS}

Con independencia de la articulación que, desde el plano teórico, se predique respecto de las sanciones administrativas, es útil destacar la renovada importancia que ellas pueden tener en la actualidad.

Para explicar dicha relevancia, es dable destacar, como cuestión previa, la progresiva utilización del Derecho como un «medio para la realización de políticas de intervención y promoción de fines, valores e intereses sociales» ${ }^{93}$, para lo cual se utilizan conceptos como el de «Derecho regulativo» (Habermas) ${ }^{94}$, «Derecho dúctil» (G. Zagrebelsky) o de «rematerialización» del Derecho (M. la Torre) ${ }^{95}$ _, los cuales dan cuenta del progresivo desplazamiento —incluido el plano del método jurídico ${ }^{96}$

91 Claus-Wilhem CANARIS, Función, estructura y falsación de las teorías jurídicas (traducción por Daniela BRÜCKNER y José Luis DE CASTRO), Civitas, Madrid, 1995, pp. 35-36.

92 Elio CASETTA, «Sanzione amministrativa», en Digesto delle Discipline Pubblicistiche. Vol. XIII, 4. ${ }^{a}$ ed., Unione Tipografico-Editrice Torinese, Torino, 1997, p. 598.

93 Manuel CALVO GARCÍA, "Transformaciones jurídicas y teoría del derecho», en Anuario de Filosofía de Derecho, núm. 28, 2012, p. 37 y, del mismo autor, Transformaciones del Estado y del Derecho, Universidad Externado de Colombia, Bogotá, 2005, p. 29.

94 Jürgen HABERMAS, Facticidad y validez. Sobre el derecho y el Estado democrático de Derecho en términos de teoría del discurso (introducción y traducción por Manuel JIMÉNEZ REDONDO), Trotta, Madrid, 1998, pp. 537-538 y 547.

${ }^{95}$ En tanto las normas estatales se dirigen «hacia valores sustantivos y su reformulación (por lo que concierne a su contenido) como actos administrativos, es decir, como intervenciones directas y específicas en todos los ámbitos de la vida social». Massimo LA TORRE, «Derecho y conceptos de derecho. Tendencias evolutivas desde una perspectiva europea», en Revista del Centro de Estudios Constitucionales, núm. 16, 1993, p. 70.

96 Según expone D. Grimm, desde el punto de vista metodológico, hoy se permite aquello que condenaron P. Laband y O. Mayer por «acientífico, esto es, la atención a los valores acuñados en el derecho, el uso de los fines o funciones que una norma debe satisfacer, el análisis de los elementos de realidad en la que los objetivos de la disposición deben realizarse, la atención a los efectos de las distintas variantes interpretativas y el apoyo en el conocimiento de las disciplinas vecinas.» Dieter GRIMM, Sobre la identidad del Derecho Público (traducción por Miguel AZPITARTE SÁNCHEZ), Fundación Coloquio Jurídico Europeo y Centro de Estudios Políticos y Constitucionales, Madrid, 2015, p. 38. 
y, por lo mismo, la formación de conceptos jurídicos ${ }^{97}$ — desde un enfoque formal y racional del fenómeno jurídico a otro racional sustantivo caracterizado por contener y perseguir criterios de orden material (sociales, económicos, etc.) ${ }^{98}$, expresivos de determinados objetivos políticos ${ }^{99}$.

Ejemplo claro de ello son las Constituciones posteriores a la Segunda Guerra Mundial, que no se limitan ya a establecer habilitaciones de poder a los órganos públicos (seńaladamente, al legislador), «sino que pone[n] ella[s] misma[s] reglas de conducta o, por lo menos, principios sustantivos hacia la realización de los cuales tiene que orientarse la intervención del legislador» ${ }^{100}$.

Según expone Calvo García, esta forma de comprender el Derecho exige, entre otros aspectos, que las normas sean efectivas y la articulación y puesta en funcionamiento de un marco jurídico de «intervención que asuma el desarrollo de los programas y la aplicación de normativas de protección y promoción» ${ }^{101}$ de dichos fines, valores e intereses, acuñándose el término de «implementación» para referirse al conjunto de medios institucionales, técnicas, recursos económicos y humanos dispuestos para la ejecución de las pertinentes "políticas públicas y programas de intervención» ${ }^{102}$.

Pues bien, como bien advierte Parejo Alfonso, la comprensión de que también es función del Derecho su efectiva realización (al igual que la de regular el ejercicio de los poderes públicos) comporta la exigencia de articular una «infraestructura» adecuada a los procesos necesarios para tal realización, señaladamente, la programación de su actuación administrativa a través de la asignación de tareas y el control del cumplimiento de estas ${ }^{103}$, toda vez que, como hemos destacado, la efectividad de las políticas y programas legales y, por tanto, los resultados pretendidos - p. eje., la tutela del consumidor, la salud, las prestaciones sociales, o, en general, el funcionamiento de un sector regulado, etc.—, requiere que las reglas y estándares establecidos al efecto sean observados y, por lo mismo, que sus destinatarios ajusten su actuar a lo en ellas dispuesto ${ }^{104}$.

${ }^{97}$ «Los conceptos [jurídicos] no son entidades abstractas, estables, que articulan un orden inmanente. Los conceptos deben ser útiles para la realización de los fines del poder público.» Silvia DÍEZ SASTRE), La formación de conceptos en el Derecho Público. Un estudio de metodología académica: definición, funciones y criterios de formación de los conceptos jurídicos, Marcial Pons, Madrid, 2018, p. 67. (La cursiva es del original).

98 CALVO GARCÍA, 2005: 11-12.

99 «Los objetivos políticos y las medidas políticas que traducen esos objetivos a la práctica solo cobran fuerza vinculante merced a su forma jurídica.» HABERMAS, 1998: 559.

100 LA TORRE, 1993: 71.

101 CALVO GARCÍA, 2005: 11-12.

102 CALVO GARCÍA, 2005: 73.

103 PAREJO ALFONSO, 2012 a: 55-56, y, 2012 b: 409. Agrega el autor que, por ello, el Derecho se ha convertido en un instrumento de «dirección de la actuación de todo tipo de sujetos para la efectividad de los procesos sociales, es decir, evitar perturbaciones en estos y, por tanto, no solo, ni preferentemente, de organización y control de situaciones y relaciones sociales y del tráfico de bienes» (p. 29) y (pp. 393-394), respectivamente.

104 Ya K. Hesse afirmó que la realización de la Constitución requiere que sus preceptos efectivamente motiven y determinen la conducta humana, de tal suerte que para que sus normas se encuentren en «vi- 
Ello exige recurrir a «saberes» especializados (ajenos al Derecho) al objeto de alcanzar la realización efectiva de los programas normativos, lo que ha conducido al paulatino desplazamiento de los ordenamientos tradicionales hacia el Derecho administrativo y, por lo mismo, se alude a la «administrativización» del Derecho en diversos ámbitos de la realidad ${ }^{105}$.

En el contexto puntualizado, se advierte que las sanciones administrativas pueden tener una renovada importancia con miras a lograr la concreción de los resultados apetecidos por el orden jurídico ${ }^{106}$ : pues, en efecto, concebidas como instrumentos dirigidos hacia una orientación sustantiva o material $-\mathrm{y}$, por lo mismo, requeridas de una articulación en función de la obtención de objetivos y resultados específicos-, las normas jurídicas deben ser eficaces en la ejecución de la regla o estándar respectivo por parte de la Administración.

Justamente, entre las técnicas que se han diseñado al efecto para llevar a cabo tal ejecución — ante la infracción de aquellas reglas — se hallan las sanciones administrativas ${ }^{107}$, a fin de que los agentes ajusten su actuar a los deberes jurídicos previstos en las mismas.

En concordancia con ello, es menester destacar que en el Derecho anglosajón se utiliza el término «enforcement» para referirse al proceso de «la ejecución o aplicación de las normas por parte de las administraciones o del gobierno, esto es, a hacerlas cumplir [...], a la obligación y facultad de aplicar las normas a las personas físicas y jurídicas, aplicación que, para el caso de esta ley, implica el ejercicio de potestades administrativas de gravamen (reglamentaria, de autorización, sancionadora, etc.) y que, por tanto, acarrea obligaciones para dichas personas, e incluso, la imposición de sanciones administrativas o penales como consecuencia de su incumplimiento» ${ }^{108}$.

gor» no solo deben existir hipotéticamente, sino realmente. Agregó que, por lo mismo, la Constitución, así como todo orden jurídico, «precisa de su actualización por medio de la actividad humana, su fuerza normadora depende de la disposición para considerar como vinculantes sus contenidos y de la resolución de realizar estos contenidos incluso frente a resistencias». Konrad HESSE, «Concepto y cualidad de la Constitución», en Escritos de Derecho Constitucional. Selección (introducción y traducción por Pedro CRUZ VILLALÓN), Centro de Estudios Constitucionales, Madrid, 1983, pp. 26-28.

105 Cfr. CALVO GARCÍA, 2005: 72-74.

106 «La connatural pretensión del Derecho de conseguir la realización de los fines a los que se orienta su regulación, incluso cuando la voluntad de los sujetos a los que se dirige se resiste o se opone, abre inevitablemente la vía del recurso a la coacción». FERNÁNDEZ-GALIANO y DE CASTRO CID, 1994: 282.

107 Según S. Shavell, el enforcement de las regulaciones — como las de seguridad— frecuentemente se llevan a cabo a través de sanciones impuestas por el incumplimiento de requisitos reglamentarios. Steven SHAVELL, «The Optimal Structure of Law Enforcement», en Journal of Law and Economic, Vol. XXXVI, 1993, pp. 259 y 279.

108 Antonio José SANCHÉZ SAÉZ, «La potestad sancionadora en el Derecho comparado: Reino Unido", en Documentación administrativa, núms. 282-283 (ejemplar dedicado a: La potestad sancionadora de las Administraciones Públicas. Tomo II), 2009, p. 100, nota 26. En términos más generales se ha puntualizado que la enforcement function se trata de «la genérica o específica habilitación para ejecutar y controlar la ejecución de lo dispuesto en las leyes y, en particular, todo lo relacionado con las conductas consideradas como infracción a los efectos de la imposición del castigo que corresponda, 
Al respecto, la doctrina ha anotado que el Derecho no se limita a alterar las posiciones normativas de los ciudadanos, sino que puede autorizar el enforcement de tales alteraciones: el orden jurídico reclama, así, que la ejecución de sus directivas sea respaldada, en última instancia, con el uso de la fuerza ${ }^{109}$; aún más, el recurso al enforcement procedería, justamente, cuando sea necesario contribuir a la eficacia de la normativa de que se trate ${ }^{110}$.

En tal sentido, según se ha argumentado convincentemente por J. Kleinfeld, el legal enforcement constituye una actividad a través de la cual se aplica un poder constituido acorde al Derecho con el objeto de hacer realidad los dictados del orden jurídico y, en ese sentido, se vincula con la eficacia basada en el cumplimiento normativo, aludiéndose, así, al enforcement como eficacia. Añade, tras explicar que el concepto de eficacia se forma a partir de los subconceptos de realidad y poder (en el sentido de Kant), que el Derecho es eficaz si tiene el poder de lograr que el contenido de las normas se concrete en el mundo real ${ }^{111}$, de suerte que — como destaca B. Fissell ${ }^{112}$ — las reglas jurídicas puedan producir una modificación entre lo que piensa el sujeto y su acción real.

Desde tal enfoque, se entiende que se afirme por B. Morgan y K. Yeung que es a través del enforcement que un conjunto de normas legales diseñadas para influir en el comportamiento humano e institucional se traduce en la realidad social ${ }^{113}$, lo que resulta relevante en un contexto en el que el Derecho es considerado un instrumento para la realización de políticas o programas normativos enderezados a la consecución efectiva de determinados valores o fines.

Nótese que este predicamento se halla en armonía con lo antes apuntado, en cuanto a que para caracterizar la eficacia de la norma no basta con la mera coincidencia entre la conducta y lo prescrito en la regla. Se requiere algo más: pues, en efecto, la regla debe operar como una razón para la acción, de modo que su existencia motive el actuar del agente. Siendo así, se advierte que las expresiones de eficacia como cumplimiento y de eficacia como enforcement, en tanto apuntan en el mismo sentido, operan como conceptos equivalentes.

incluido el criminal o penal». Andrés BETANCOR, «Derecho administrativo sancionador en el sistema jurídico británico: Regulatory Enforcement and sanctions act 2008», en Revista General de Derecho Administrativo, núm. 19, 2009, pp. 10-11.

109 Grant LAMOND, «Coercion and the nature of Law», en Legal Theory, Vol. 7, 2001, p. 55. Añade que, por ello, al igual que el vínculo entre deberes y sanciones, el vínculo entre el sistema legal y la coerción no es constitutivo, no es que la coerción sea un componente necesario de la eficacia del Derecho o su autoridad, sino más bien justificativo: el Derecho reclama la posibilidad de reforzar sus directivas con medidas coercitivas.

110 Así, Brenner M. FISSELL, «Sanctions and Efficacy in Analytic Jurisprudence», en Rutgers Law Review, Vol. 69, 2017, p. 1641. (Accesible https://papers.ssrn.com/sol3/papers.cfm?abstract_id=3172521).

111 Joshua KLEINFELD, «Enforcement and the Concept of Law», en Yale Law Journal Online, núm. 121, 2011, pp. 300-301. (Accesible en https://papers.ssrn.com/sol3/papers.cfm?abstract_id=2166341).

112 FISSELL, 2017: 1629.

113 Bronwen MORGAN y Karen YEUNG, An Introduction to Law and Regulation: Text and Materials, Cambridge University Press, Cambridge, 2007, p. 10. 
En ese orden de ideas, la sanción administrativa aparece como un medio destinado a incitar suficientemente ${ }^{114}-\mathrm{y}$, por tanto, con pretensión de eficacia- a los destinatarios de los mandatos o prohibiciones a fin de que cumplan y respeten las reglas de modo que, en último término, se realicen aquellos objetivos cuya ejecución el legislador descargó, en su caso, en la Administración (y que, en definitiva, se reconducen a la satisfacción del interés general) en los sectores que han sido administrativizados ${ }^{115}$.

En tales condiciones, la potestad sancionadora se erige como un instrumento que, con el objeto de obtener la eficacia de las actuaciones sustantivas de la Administración ${ }^{116}$, se inserta en el marco de una determinada estructura regulatoria (normas, estándares, procedimientos, etc.), cuya articulación se realiza en función de la finalidad antes aludida (la ejecución —enforcement - de los deberes jurídicos fijados al efecto). Como recuerda Schmitd-Aßmann, la imposición eficaz del Derecho, entre otros aspectos, exige una orientación de los órganos administrativos a la coacción, toda vez el Estado de Derecho no puede tolerar que existan incumplimientos reiterados de las normas, pues de otra forma existe el peligro de que lo excepcional se convierta en regla ${ }^{117}$.

Así entendida, puede consignarse que la sanción administrativa "complementa" o «auxilia» o "refuerza» ${ }^{118}$ el ejercicio de las funciones sustantivas encargadas a la Administración ${ }^{119}$ (intervención, prestación, prevención, vigilancia, supervisión, regulación, etc.), de suerte que no resulta posible analizarla en forma aislada, sino en el contexto de la específica actividad administrativa en la que se despliega y, por lo mismo, con similar objeto y limites que aquella acción principal ${ }^{120}$.

114 Alude a la finalidad de la sanción pecuniaria de garantizar suficientemente la incitación a la realización un determinado deber, en el contexto de un requerimiento de información en el ámbito tributario, la STJUE de 16 de mayo de 2017, en el asunto Berlioz Investment Fund SA/Directeur de l'administration des contributions directes (Luxemburgo), C-682-15, ap. 18.

115 Vid., en ese sentido, PAREJO ALFONSO, 2014: 10.

116 Como afirma Nieto García, las medidas sancionadoras se integran a las administrativas materiales de la Administración como un intento más - junto con las de fomento, preventivas, cautelares, etc.- de eficacia administrativa. NIETO GARCÍA, 2012: 576.

117 Eberhard SCHMIDT-AßMANN, La teoría general del derecho administrativo como sistema (traducción de la versión alemana de 1998 por Mariano BACIGALUPO SAGGESE, et al.), Instituto Nacional de Administración Pública y Marcial Pons, Madrid, 2003, pp. 68-69.

118 SILVA SÁNCHEZ, 2001:125.

119 Idea que se encuentra, entre otros, en NIETO GARCÍA, 2012: 53; HUERGO LORA, 2007: 139 y PAREJO ALFONSO, 2014:10. En esa línea, se ha sostenido que «el Derecho administrativo sancionador es [...] un derecho adjetivo, complementario de cada una de las funciones y del que la Administración se encuentra provista para el mejor cumplimiento de sus funciones, sin que eso tenga que ver con el ius puniendi y con la configuración de conductas antisociales.» Juan José BAYONA DE PEROGORDO, "El procedimiento sancionador", en Revista Información Fiscal, núm. 16, 1996, p. 21.

120 En esa línea, pero aun aludiendo a los principios de Derecho penal, vid., Manuel REBOLLO PUIG, Potestad sancionadora, alimentación y salud pública, Instituto de Administración Pública, Madrid, 1989, p. 444. 
Consecuente con esta perspectiva, se ha puntualizado por la doctrina ${ }^{121}$ que la potestad administrativa sancionadora tiene la virtualidad de operar como un instrumento relevante que, incardinado en el proceso de publicación, ejecución y aplicación de la normativa pertinente ${ }^{122}$, persigue, justamente, la efectiva observancia de los mandatos o prohibiciones pertinentes ${ }^{123}$.

De aquí, pues, que pueda compartirse la afirmación de que la efectividad y la realización del Derecho comprenden la imposición (enforcement) de las sanciones administrativas y, en su caso, la ejecución forzosa, teniendo en consideración que estas «se incardinan en un proceso que comienza con la legislación, sigue con la aplicación concreta de esa normativa abstracta, y termina, si se hace necesario, con la coacción» ${ }^{124}$.

Habida cuenta de lo expuesto, cabe predicar entonces que el establecimiento y la imposición de sanciones administrativas «son, pues, elementos que forman parte de la estructura funcional del Derecho" ${ }^{125}$ administrativo: se entiende, en tal sentido, que se considere a la sanción administrativa como una etapa más del «ciclo» de la regulación ${ }^{126}$ o parte integrante del cumplimiento efectivo de la regla (enforcement) o, en todo caso, como una forma de garantizar el cumplimiento normativo ${ }^{127}$, señaladamente, el orden jurídico-administrativo.

121 MONTT OYARZÚN, 2011: p. 75-76.

122 Recuérdese, en ese orden, las palabras de V. Frosini: «La publicación de una ley es el primer paso para que se lleve a cabo el proceso de circulación de las informaciones y de las prescripciones que dicha ley contiene, y que culmina y concluye en el momento de su aplicación o ejecución concreta, que constituye asi la integración necesaria de la función técnica de la ley.» Vittorio FROSINI, La letra y el espiritu de la ley (traducción por Carlos ALARCÓN CABRERA y Fernando LLANO ALONSO), Ariel, Barcelona, 1995, pp. 42-43. (La cursiva es nuestra).

123 Vid., el reciente e interesante trabajo de Alejandro HUERGO LORA, «Las sanciones administrativas en el marco del law enforcement», en Diego ZEGARRA VALDIVIA (Coor.), La proyección del Derecho Administrativo Peruano. Estudios por el Centenario de la Facultad de Derecho de la PUCP, Palestra, Lima 2019.

${ }^{124}$ Ricardo GARCÍA MACHO y José Luis BLASCO DÍAZ, «La disciplina urbanística», en Documentación Administrativa, núms. 282-283 (ejemplar dedicado a: La potestad sancionadora de las Administraciones Públicas. Tomo II), 2009, p. 292.

125 FERNÁNDEZ-GALIANO y DE CASTRO CID, 1994: 282.

126 En esa línea, Carol HARLOW y Richard RAWLINGS, Law and Administration, 3. ${ }^{\mathrm{a}}$ ed., Cambridge University Press, Cambridge, 2009, pp. 242 y ss. Vid., asimismo, con citas respectivas, Pablo SOTO DELGADO, «Sanciones administrativas como medidas de cumplimiento del Derecho: un enfoque funcional y responsivo aplicado al régimen sancionatorio ambiental», en Revista Ius et Praxis, Año 22, núm. 2, 2016, pp. 194 y ss. (Accesible en https://www.scielo.cl/scielo.php?script=sci_ arttexterpid=S0718-00122016000200007\#n27).

127 En el reconocido informe Macrory se lee que se ha considerado la literatura académica, la experiencia internacional y las respuestas proporcionadas a través de un proceso de consulta y se ha encontrado que las sanciones administrativas son una forma de garantizar el cumplimiento normativo. Richard MACRORY, Regulatory Justice: Making Sanctions Effective. Final Report, Macrory Review. Better Regulation Executive, London, 2006, p. 42. (http://webarchive.nationalarchives.gov.uk/20121205164501/ http://www. bis.gov.uk/files/file44593.pdf). 


\section{BIBLIOGRAFÍA}

ATIENZA RODRÍGUEZ, Manuel, «Diez consejos para escribir un buen trabajo de dogmática», en Isonomía: Revista de Teoría y Filosofía del Derecho, núm. 3, 1995.

—, Introducción al derecho, 7. a ed., Fontamara, Mexico D.F., 2011.

BAYÓN, Juan Carlos, La normatividad del Derecho: deber jurídico y razones para la acción, Centro de Estudios Constitucionales, Madrid, 1991.

BAYONA DE PEROGORDO, Juan José, «El procedimiento sancionador», en Revista Información Fiscal, núm. 16, 1996.

BETANCOR, Andrés, «Derecho administrativo sancionador en el sistema jurídico británico: Regulatory Enforcement and sanciones act 2008", en Revista General de Derecho Administrativo, núm. 19, 2009.

BOBBIO, Norberto, Teoria General del Derecho (traducción por ROZO ACUŃA, Eduardo), Editorial Debate, Madrid, 1991.

CAIRNS, Huntington, Legal Philosophy from Plato to Hegel, Johns Hopkins University Press, Baltimore, 1949.

CALVO GARCÍA, Manuel, Transformaciones del Estado y del Derecho, Universidad Externado de Colombia, Bogotá, 2005.

—, «Transformaciones jurídicas y teoría del derecho», en Anuario de Filosofía de Derecho, núm. 28, 2012.

CANARIS, Claus-Wilhem, Función, estructura y falsación de las teorias jurídicas (traducción por BRÜCKNER, Daniela y DE CASTRO, José Luis), Civitas, Madrid, 1995.

CASETTA, Elio, «Sanzione amministrativa», en Digesto delle Discipline Pubblicistiche. Vol. XIII, 4. a ed., Unione Tipografico-Editrice Torinese, Torino, 1997.

CEREZO MIR, José, "Límites entre el Derecho penal y el Derecho administrativo», en Anuario de derecho penal y ciencias penales, Tomo XXVIII, Fascículo II, 1975.

DELGADO ECHEVERRÍA, Jesús, Validez de normas y de actos jurídicos. Estudios de Teoría General desde el derecho privado, Marcial Pons, Madrid, 2019.

DÍEZ SASTRE, Silvia, La formación de conceptos en el Derecho Público. Un estudio de metodología académica: definición, funciones y criterios de formación de los conceptos jurídicos, Marcial Pons, Madrid, 2018.

D’AGOSTINO, Francesco, Filosofía del derecho (traducción por RODRÍGUEZ ITURBE, José), Editorial Temis, Bogotá, 2007.

FEIJOO SÁNCHEZ, Bernardo, «Sobre la "Administrativización” del Derecho penal en la "Sociedad del Riesgo"", en AAVV, Derecho y justicia penal en el siglo XXI: Liber amicorum en homenaje al profesor Antonio González-Cuéllar Garcia, editorial Constitución y Leyes, Madrid, 2006.

FERNÁNDEZ-GALIANO, Antonio y DE CASTRO CID, Benito, Lecciones de Teoría del Derecho y Derecho Natural, reim. revisada, Editorial Universitas, Madrid, 1994.

FERRARI, Vicenzo, Funciones del Derecho (traducción por AÑON ROIG, María José y DE LUCAS MARTIN, Javier), Editorial Debate, Madrid, 1989.

FISSELL, Brenner M., «Sanctions and Efficacy in Analytic Jurisprudence», en Rutgers Law Review, Vol. 69, 2017.

FROSINI, Vittorio, La letra y el espiritu de la ley (traducción por ALARCÓN CABRERA, Carlos y LLANO ALONSO, Fernando), Ariel, Barcelona, 1995.

GARCÍA MACHO, Ricardo y BLASCO DÍAZ, José Luis, «La disciplina urbanística», en Documentación Administrativa, núms. 282-283 (ejemplar dedicado a: La potestad sancionadora de las Administraciones Públicas. Tomo II), 2009.

GÓMEZ, Rosa Fernanda, «Potestad sancionadora de la Administración: la conveniencia de su reconocimiento constitucional», en Revista de Derecho Administrativo Económico, núm. 32, 2020.

GREPPI, Andrea, «Eficacia», en Euronomía. Revista en cultura de la Legalidad, núm. 3, 2012. (Accesible https://e-revistas.uc3m.es/index.php/EUNOM/article/view/2126/1057). 
GRIMM, Dieter, Sobre la identidad del Derecho Público (traducción por AZPITARTE SÁNCHEZ, Miguel), Fundación Coloquio Jurídico Europeo y Centro de Estudios Políticos y Constitucionales, Madrid, 2015.

HABERMAS, Jürgen, Facticidad y validez. Sobre el derecho y el Estado democrático de Derecho en términos de teoría del discurso (introducción y traducción por JIMÉNEZ REDONDO, Manuel), Trotta, Madrid, 1998.

HARLOW, Carol y RAWLINGS, Richard, Law and Administration, 3. a ed., Cambridge University Press, Cambridge, 2009.

HART, Herbert L. A., El concepto de Derecho (traducción por CARRIÓ, Genaro R.), reim. 2. a ed., Abeledo-Perrot, Buenos Aires, 2007.

HESSE, Konrad, "Concepto y cualidad de la Constitución", en Escritos de Derecho Constitucional. Selección (introducción y traducción por CRUZ VILLALÓN, Pedro), Centro de Estudios Constitucionales, Madrid, 1983.

HIERRO, Liborio, La eficacia de las normas jurídicas, Ariel, Barcelona, 2003.

HOFFMANN-RIEM, Wolfgang, «Libertad y Seguridad en la estela de los atentados terroristas», en Revista Teoría y Realidad constitucional, núms. 12-13, 2003.

HUERGO LORA, Alejandro, "Ponencia sobre Derecho penal y administrativo», en II Seminario de Teoría y Método del Derecho Público, celebrado en la Universidad Autónoma de Madrid, Madrid, 29 de noviembre de 2013, 2013.

—, Las sanciones administrativas, Iustel, Madrid, 2007,

—, «Diferencias de régimen jurídico entre las penas y las sanciones administrativas que pueden y deben orientar su utilización por el legislador, con especial referencia a los instrumentos para la obtención de pruebas», en HUERGO LORA, Alejandro (dir.) Problemas actuales del Derecho administrativo sancionador, Iustel, Madrid, 2018.

—, «Las sanciones administrativas en el marco del law enforcement», en ZEGARRA VALDIVIA, Diego (Coor.), La proyección del Derecho Administrativo Peruano. Estudios por el Centenario de la Facultad de Derecho de la PUCP, Palestra, Lima 2019.

KELSEN, Hans, Teoría general del Derecho y del Estado (traducción por GARCÍA MÁYNEZ, Eduardo), reim. 3. a ed., Universidad Nacional Autónoma de México, México D.F., 1983.

-, Teoría general de las normas (traducción por DELORY JACOBS, Hugo Carlos), Editorial Trillas, México D.F., 1994.

KLEINFELD, Joshua, «Enforcement and the Concept of Law», en Yale Law Journal Online, núm. 121, 2011. (Accesible en https://papers.ssrn.com/sol3/papers.cfm?abstract_id=2166341).

LA TORRE, Massimo, «Derecho y conceptos de derecho. Tendencias evolutivas desde una perspectiva europea», en Revista del Centro de Estudios Constitucionales, núm. 16, 1993.

LAMOND, Grant, "Coercion and the nature of Law», en Legal Theory, Vol. 7, 2001.

LETELIER, Raúl, «Sanciones administrativas regulatorias: tres premisas sobre su función», en Revista de Derecho Administrativo Económico, núm. 32, 2020.

LUMIA, Guiseppe, Principios de Teoría e ideología del Derecho (traducción por RUIZ MIGUEL, Alfonso), Editorial Debate, Madrid, 1978.

MAcCORMICK, Neil, Derecho legal y Socialdemocracia. Ensayos sobre filosofía jurídica y politica (traducción por GONZÁLEZ SOLAR, María Lola), Tecnos, Madrid, 1990.

MACRORY, Richard, Regulatory Justice: Making Sanctions Effective. Final Report, Macrory Review. Better Regulation Executive, London, 1990. (http://webarchive.nationalarchives.gov.uk/20121205164501/ http://www.bis.gov.uk/files/file44593.pdff).

MATTES, Heinz, Problemas de Derecho Penal Administrativo. Historia y Derecho Comparado (traducción por RODRÍGUEZ DEVESA, José María), Edersa, Madrid, 1979.

MAURACH, Reinhart, Tratado de Derecho penal. Vol. I (traducción y notas por CÓRDOVA RODA, Juan), Ariel, Barcelona, 1962.

—, Derecho penal. Vol. 1: Teoría general del Derecho penal y estructura del hecho punible (versión actualizada por ZIPF, Heinz y traducida de la 7.a ed. alemana por BOFILL GENZSCH, Jorge y AIMONE GIBSON, Enrique), Astrea, Buenos Aires, 1994. 
MELOSSI, Darío, El Estado del control social. Un estudio sociológico de los conceptos de estado y control social en la conformación de la democracia (traducción por MUR UBASART, Martín), Siglo Veintiuno editores, México D.F., 1992.

MORAND, Charles A., "La sanction», en Travaux CETEL, núm. 36, 1990. (Accesible en https://archive-ouverte.unige.ch/unige:4959).

MORGAN, Bronwen y YEUNG, Karen, An Introduction to Law and Regulation: Text and Materials, Cambridge University Press, Cambridge, 2007.

MUÑOZ CONDE, Francisco, Derecho Penal y Control Social, Fundación Universitaria de Jerez, Madrid, 1985.

—, Tratado de Derecho Administrativo y Derecho Público General, Vol. 1, 2a ed., Iustel, Madrid, 2006.

NAVARRO, Pablo, La eficacia del Derecho. Una investigación sobre la Existencia y Funcionamiento de los Sistemas Jurídicos, Centro de Estudios Constitucionales, Madrid, 1990.

-, Dinámica y eficacia del derecho. Un análisis conceptual de la obediencia y aplicación del derecho, Fontomara, México D.F., 2017.

NAVARRO CARDOSO, Fernando, «Expulsión "penal” de extranjeros: una simbiosis de Derecho penal "simbólico" y Derecho penal del "enemigo" ", en Revista de Derecho Penal y Criminología, 2. a Época, núm. 17, 2006.

NIETO GARCÍA, Alejandro, Derecho administrativo sancionador, 5. ${ }^{\mathrm{a}}$ ed., Tecnos, Madrid, 2012.

NINO, Carlos Santiago, Introducción al análisis del Derecho, 2. ${ }^{a}$ ed., ampliada y revisada (12. a reimp.) Ariel, Barcelona, 2003

NOVOA MONREAL, Eduardo, "Algunas reflexiones sobre el Derecho de Castigar del Estado», en Anuario de Filosofía del Derecho, Tomo I, 1984.

—, "Algunas reflexiones sobre el Derecho de Castigar del Estado», en BERGALLI, Roberto y BUSTOS, Juan (directores y compiladores), El Poder Penal del Estado. Homenaje a Hilde Kaufmann, Depalma, Buenos Aires, 1985.

PAREJO ALFONSO, Luciano, «La deriva de las relaciones entre los derechos administrativos y penal. Algunas reflexiones sobre la necesaria recuperación de su lógica sistemática», en Revista de Documentación Administrativa, núms. 284-285, 2009.

—, «Algunas reflexiones sobre la necesidad de depuración del status de la sanción administrativa», en Revista General de Derecho Administrativo, núm. 36, 2014.

—, Transformación y ¿reforma? del Derecho Administrativo en España, Instituto Nacional de Administración Pública y Global Law Press, Sevilla, 2012 a.

—, "Transformación y ¿reforma? del Derecho Administrativo en España», en BARNES, Javier (ed.), Innovación y Reforma en el Derecho Administrativo, 2. ${ }^{\mathrm{a}}$ ed., Instituto Nacional de Administración Pública y Global Law Press, Sevilla, 2012 b

PINTORE, Anna, «A Rule-Governed Gunman Writ Large? El puesto de la Coerción en "The Concept of law"», en Doxa: Cuadernos de filosofía del derecho, núm. 37, 2014.

RADCLIFFE-BROWN, Alfred R., Estructura y función en la sociedad primitiva (traducción por PÉREZ, Ángela), Planeta-De Agostini, Barcelona, 1986.

RAZ, Joseph, La autoridad del derecho. Ensayos sobre el derecho y la moral (traducción y notas por TAMAYO Y SALMORÁN, Rolando), 2. ${ }^{a}$ ed., Universidad Nacional Autónoma de México, México D.F., 1985.

REHBINDER, Manfred, Sociología del Derecho (traducción por ROBLES MORCHÓN, Gregorio), Ediciones Pirámide, Madrid, 1981.

SANCHÉZ SAÉZ, Antonio José, «La potestad sancionadora en el Derecho comparado: Reino Unido», en Documentación administrativa, núms. 282-283 (ejemplar dedicado a: La potestad sancionadora de las Administraciones Públicas. Tomo II), 2009.

SCHAUER, Frederick, Fuerza de Ley (traducción y estudio preliminar por RAPETTI, Pablo Ariel), Palestra editores, Lima, 2015.

SCHMIDT-AßMANN, Eberhard, La teoría general del derecho administrativo como sistema (traducción de la versión alemana de 1998 por Mariano BACIGALUPO SAGGESE, et al.), Instituto Nacional de Administración Pública y Marcial Pons, Madrid, 2003. 
SHAVELL, Steven, "The Optimal Structure of Law Enforcement", en Journal of Law and Economic, Vol. XXXVI, 1993.

SILVA SÁNCHEZ, Jesús, La expansión del Derecho Penal. Aspectos de la Política criminal en las sociedades posindustriales, 2. ${ }^{\text {a }}$ ed., revisada y ampliada, Civitas, Madrid, 2001.

SOLANES CORELLA, Ángela, "El camino de la ética a la política: la sanción en Jeremy Bentham y John Stuart Mill», en Anuario de Filosofía del Derecho, núm. 23, 2006.

SORIANO, Ramón, Sociología del Derecho, Ariel, Barcelona, 1997.

SOTO DELGADO, Pablo, «Sanciones administrativas como medidas de cumplimiento del Derecho: un enfoque funcional y responsivo aplicado al régimen sancionatorio ambiental», en Revista Ius et Praxis, Año 22, núm.2, 2016.

SUAY HERNÁNDEZ, Celia, «Refutación del ius puniendi», en ARROYO ZAPATERO, Luis y BERDUGO GÓMEZ DE LA TORRE, Ignacio (coords.), Homenaje al Dr. Marino Barbero Santos: in memorian, Universidad de Castilla-La Mancha y Universidad de Salamanca, vol. I, 2001.

TAMAYO Y SALMORÁN, Rolando, El Derecho y la ciencia del Derecho, Universidad Nacional Autónoma de México, México D.F., 1984, p. 25.

TYLER, Tom, «Legitimidad y justicia penal: los beneficios de la autorregulación», en La obediencia del Derecho (estudio preliminar de PÉREZ CORREA, Catalina y traducción por MORALES DE SETÉN RAVINA, Carlos), Siglo del Hombre editores, Bogotá, 2014 a.

—, «La legitimidad como cuestión teórica», en La obediencia del Derecho (estudio preliminar de PÉREZ CORREA, Catalina y traducción por MORALES DE SETÉN RAVINA, Carlos), Siglo del Hombre editores, Bogotá, 2014 b.

VON WRIGHT, G. Henrik, Norma y acción. Una investigación lógica (traducción por GARCÍA FERRERO, Pedro), Tecnos, Madrid, 1979.

ZANOBINI, Guido, Le sanzioni amministrative, Fratelli Boca, Torino, 1924.

-, Curso de Derecho administrativo. Vol. I. Parte General (traducción por MASNATTA, Héctor y actualizada por PICONE, Francisco Humberto), Ediciones Arayú, Buenos Aires, 1954. 
